\title{
Analysis of Energy Efficiency of Rotate Flettner Rotor Based on Variation in Wind Direction and Rotor's Material
}

Jürgen Siegl ${ }^{1}$, Irfan Syarief Arief ${ }^{2}$, Akbar Rizqi Hartawan ${ }^{3}$

(Received: 01 August 2019 / Revised: 18 June 2020 / Accepted: 25 June 2020)

\begin{abstract}
It rotates on its axis to utilize the airflow from the wind and help the ship to generate additional thrust force by using the principle of magnus effect. This additional thrust force produced by the flettner rotor helps to reduce the fuel consumption which used as an energy source for the main or auxiliary engine. However, the flettner rotor has possibilities to operate in a certain different condition which can affect the efficiency of the flettner rotor usage. The discussion is to find out how much power is needed to rotate a rotor based on the variation of the material being used, how does the wind direction affect the performance of the flettner rotor as an alternative ship propulsion system, how does the energy efficiency get affected by the variation of material and the wind direction. From the discussion of this paper, it is concluded that aluminum is the material that requires the least power to rotate a flettner rotor with $77,2276 \mathrm{~kW}$ on the speed of $14.4 \mathrm{rad} / \mathrm{s}$ and it gives its maximum contribution when the wind direction towards the flettner rotor is coming through the port side of the ship with the angle of $90{ }^{\circ}$ and the flettner rotor rotates in clockwise direction. It is also concluded that the best configuration of flettner rotor to produce a good energy efficiency are by using aluminum as the rotor's material, having wind that coming through from the angle of $90^{\circ}$, and the flettner rotor rotates at $14.4 \mathrm{rad} / \mathrm{s}$ with apparent wind speed at $7.2 \mathrm{~m} / \mathrm{s}$. This configuration can save fuel consumption of the ship up until $570.768 \mathrm{~kg}$ on $5000 \mathrm{~km}$ voyage.
\end{abstract}

Keywords-CFD, energy efficiency, flettner rotor, materials, wind direction

\section{INTRODUCTION}

$\mathrm{T}$ he shipping industry is an industry involves a huge, multi-billion of dollars around it. This industry is the lifeblood of the world's economy and it accounts for $90 \%$ of the world's trade. Ships are able to carry goods in quantities that are impossible to transport by the other mode of transportations. Cited as the most energy efficient mode of transport, it contains various challenges inside the industry. Currently, the shipping industry contributes for approximately $3 \%$ of the total $\mathrm{CO} 2$ value in the world and it's expected to increase around $20-25 \%$ of global anthropogenic $\mathrm{CO} 2$ by 2050 due to growth in international trade and other industry sector decarbonisation effort (Rehmatulla, 2015). This growth in international trade will directly affect the amount of shipping operations to be done in order to fill the needs. However, this activity also mean that there will be an increase in fuel consumption and expenses for the operation. Furthermore, this increasing value of fuel consumption results in increasing value of $\mathrm{CO} 2$ produced [1]. This is dangerous to the environment and effects significantly to the human's health. According to a Danish study from 2011, smokestack emissions from international shipping kill approximately 50,000 people a year in Europe, at an annual cost to society of more than $€ 58$ billion. These problems cannot be left unsolved and

Jürgen Siegl, Hochschule Wismar, Rostock, 18119, Germany. Email: juergen.siegl@hs-wismar.de

Irfan Syarief Arief, Departement of Marine Engineering, Institut Teknologi Sepuluh Nopember, Surabaya, 60111, Indonesia. E-mail: irfansyah@its.ac.id

Akbar Rizqi Hartawan, Departement of Marine Engineering, Institut Teknologi Sepuluh Nopember, Surabaya, 60111, Indonesia. E-mail: hartawanakbar@gmail.com actions must be taken immediately in order to deal with these problems.

Several technologies and regulations have been identified to solve these problems. One of the solutions that might come up to meet this issue is using alternative energy as a source of energy. The alternative energy that has been applied to the shipping industry is the utilization of wind as a source of energy through the media flettner rotor.

Flettner rotor is an object which shaped cylindrical It installed vertically on the ship's body and rotate on its axis to utilize the airflow from the wind and help the ship to generate additional thrust force by using the principle of magnus effect. This additional thrust force produced by the flettner rotor helps to reduce the fuel consumption which used as an energy source for the main or auxiliary engine. The force itself depends on several parameters that affects the rotor's work such as the wind, the turbine's geometry, the turbine's operational condition, and the ships factor.

The Flettner Rotor is a simple technology that utilizes the working principle of the magnus effect where in its use, the rotor must rotate to produce a difference in pressure which will cause the thrust to emerge. But in fact, to be able to produce an optimal thrust, the flettner rotor is faced with several kinds of conditions that can lead to the fluctuation of efficiency value from the rotor. Several things that can affect the performance efficiency of the flettner rotor are the power needed to rotate the rotor and the direction of the wind. This research paper will focus on calculating the power consumption for the rotor, the influence of wind direction for the rotor, and the performance efficiency of the rotor for its implementation on ship.

To analyse the flettner rotor, Computational Fluid Dynamic or CFD method is often chose to help researchers understand about the rotor work better. CFD is a numerical simulation method and data structures that 
analyse the characteristics that involves fluid flows on a machine that has been designed. Computers are used to calculate the free-stream flow simulation of the fluid and the interaction between the fluid and surfaces defined by boundary condition that has been set. It helps the engineer to simulate a machine or product so it doesn't take time and high cost. In terms of this paper, this method is able to analyse the fluid flow around the rotor and find several parameters desired.

\section{METHOD}

\section{A. Ship resistance training}

The first step of this paper is to define the ship's that will be used. This paper will use KRISO -KCS ship's model. It is a ship model that provided by the Maxsurf software and it is available to use for everyone. KRISO KCS ship's model is a ship model with 7,273 meters long in LWL, 0.51 meters wide, and draft in 0.331 meters. Later, it will be scale up to $15 \mathrm{x}$ to use it as a ship's reference for the analysis of flettner rotor energy efficiency. The process of scaling up the ship is done also by using the Maxsurf software that directly attain the information of the ship's main parameter such as its LWL, Beam, Draft, Displaced volume, Wetted area, and etc. These parameters existed later on will be used to calculate the ship's resistance once when the process of scaling up the model has been done.

When the process of scaling up is done, resistance calculation take place. Resistance or ship resistance is defined as a force needed to make a ship move in a constant velocity. There are several methods existed to calculate the resistance such as Guldhammer Harvald, Holtrop, Ayre, and etc. On this paper, the resistance calculation method used is the Holtrop method which is provided by the Maxsurf Resistance software. Now go to the software, select the "Open Design Data" and choose the Ship's data that previously made. Now the ship is ready to be analyzed.

Now choose the analysis on menu tab and select the methods option. Then there will be options shown up on the screen. It shown up various method available to calculate the resistance of ship's design inserted. Check list the "Holtrop" box and "use 19th ITTC modified formula" on screen and then press ok. Then choose desired ship's velocity on analysis and input the ship design speed range. The speed range will be from 12 knots to maximum 15 knots. Finally, the results will be shown in "results window" and give information regarding ship's resistance and engine power for the ship. Based on the result above, it is stated that the resistance value of the ship on 15 knots is $142.7 \mathrm{kN}$.

\section{B. Flettner Rotor Creation}

Now the process of designing Flettner Rotor can begin. In this paper, rotor's parameter such as its dimension, RPM, and the other is referring to the graph Figure 1 created by (A. De Marco, S. Mancini, C. Pensa, R. Scognamiglio, and L. Vitiello). There stated various value of SR, AR, CL, and CD. Each of these values are important and represent several factors to be selected in the process of designing Flettner Rotor.

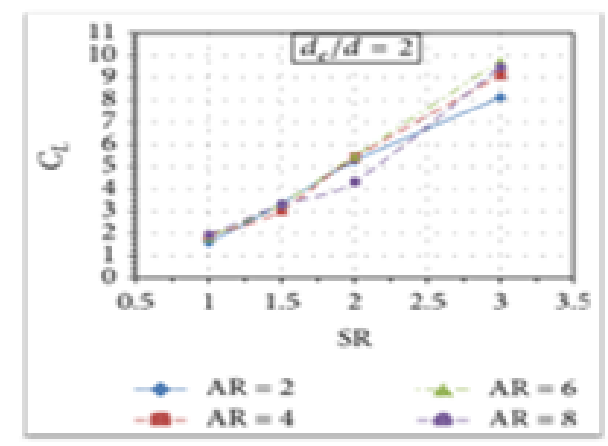

Figure. 1. AR SR CL graph.

1) Aspect Ratio

The AR of Flettner device represents the ratio between height and diameter. Thus, from this ratio the value of rotor's height and diameter can be determined. Based on the graph, the AR value chosen for this paper is 6 and the diameter value is previously to be set on 3 meters. Therefore, the value of rotor's height can be determine using this equation.

$$
A R=\frac{H(m)}{d(m)}
$$

\section{2) Spin Ratio}

It is another factor that influence the aerodynamic characteristics of a Flettner Rotor. It represents the ratio between the circumferential speed of the rotor and the free stream velocity. Based on the graph, the SR value chosen for this paper is 3 and the value of the wind speed is to be varied from 7.2 meter/second until 2.7 meter/second. Therefore, the value of rotor's RPM can be determined and varied as well. When the AR and SR value are identified, the next parameter to be decided is the end plate.

3) End Plate $S R=\frac{\Omega\left(\frac{\mathrm{rad}}{\mathrm{s}}\right) \times d(\mathrm{~m})}{2 \times u(\mathrm{~m})}$

Now the parameter to be selected is the End Plate. It has the purpose to optimize its aerodynamic efficiency by using this plate at the top of the cylinder. 


$$
E P=\frac{d e(m)}{d(m)}
$$

4) Lift \& Drag Force Calculation

Lift is a force that is perpendicular to the oncoming flow direction. It is created by an object that rotating through a moving fluid resulting in a pressure difference among the body and start to create a lift force. While drag is a force that acts opposite to the relative motion of an object moving with respect to a surrounding fluid. Sometimes it is called as an air resistance or type of friction. These forces will used as a reference for the force that the flettner rotor will produce.

$$
\begin{aligned}
& \mathrm{CD}=\frac{D(\mathrm{~N})}{0.5 \times \rho\left(\mathrm{kg} / \mathrm{m}^{3}\right) \times A\left(\mathrm{~m}^{2}\right) \times U^{2}(\mathrm{~m} / \mathrm{s})} \\
& \mathrm{CL}=\frac{L(\mathrm{~N})}{0.5 \times \rho\left(\mathrm{kg} / \mathrm{m}^{3}\right) \times A\left(\mathrm{~m}^{2}\right) \times U^{2}(\mathrm{~m} / \mathrm{s})}
\end{aligned}
$$

5) Power Calculation

In this section, the purpose of this calculation is to determine how much power needed to rotate Flettner Rotor and produce forces based on parameters being used.

$$
P(k W)=\frac{T(N m) \times \Omega(R P M)}{5252} \times 0.745
$$

Torque is defined as a force that makes an object to rotate. Just as a linear force is a push or a pull, a torque can be called as a twist to an object.

$$
T(\mathrm{Nm})=I(\mathrm{kgm} 2) \times \boldsymbol{\alpha}\left(\mathrm{rad} / \mathrm{s}^{2}\right)
$$

\section{Simulation Process}

1) Pre-Processor

Consist of the input from a flow problem that will be simulated. Defining domain, fluid properties, and boundary condition is located in this step. The object to be analysed is also going through meshing process in this step.

\section{2) Processor}

In solver step, include the stage of calculation for every iteration in parts associated with the mesh configuration and the parameters/ method being inputted

\section{3) Post Processor}

Post processing is an end step process which consist of result from the calculation. Visualization from the formulation is also can be seen in this step with variation of 2 dimension or 3-dimensional view.

\section{Wind Direction Variation}

The force value is obtained, the force resultant and the direction is obtained as well. Now, the process proceeding to see how the force produce by the flettner is working on the ship moving to the desired direction on various wind angle. This process will be done by using vector lines on Autocad software to determine its effect on the ship. The first thing to do is to prepare the data for the process. Several data needed for this process are ship's resistance, force resultant for each flettner rotor different parameter, force directions, and ship directions.

- Line Definition

The first thing to do is to create lines for each different purpose. Each line represents different value and to make it easy to understand, each line has different colour.

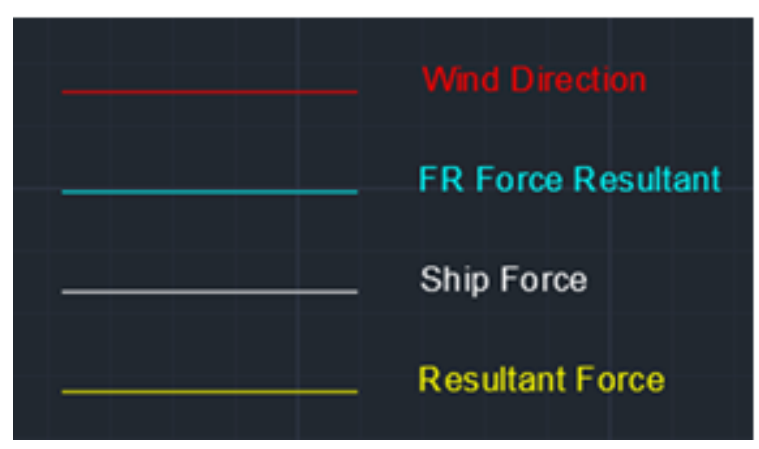

Figure. 2. Line definition.

\section{- Drawing The Line}

The next process is to draw the line based on its direction. so the first thing to draw is to draw the ship force line towards $\mathrm{x}+$ direction with dimension of the ship. Then draw the wind direction followed by the force resultant created by the wind direction (based on simulation). Move the resultant force of flettner rotor on the edge of the ship force to determine the resultant created by the flettner rotor and the ship. Draw a line that connect the edge of resultant force of flettner rotor to the zero point. This is a line that represent a resultant force between the flettner rotor and the ship. Snap to Geometry. The purpose of this automatic step is to paper a mesh obtained from previous results on geometric shapes so as to produce a smooth geometric shape. 


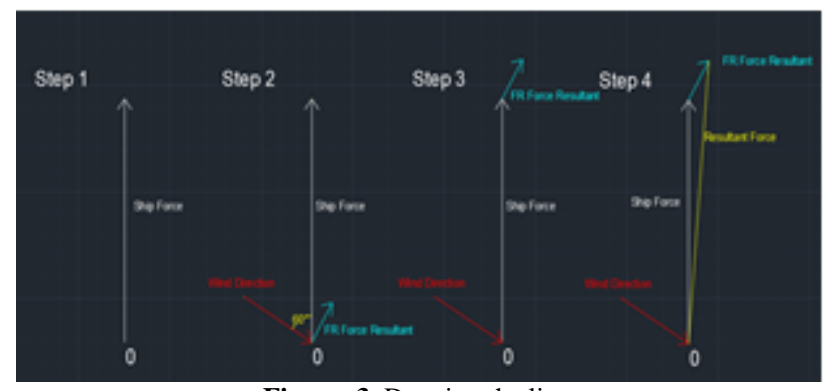

Figure. 3. Drawing the line.

Now repeat the step with variation on the wind direction and the flettner rotor resultant. It creates different value for each different parameter inserted E. Energy Efficiency Analysis

It will be going to calculate the efficiency energy for the operation of flettner rotor. This calculation will be based on the fuel consumption of main engine and auxiliary engine during a voyage. This calculation will compare the operation of ship with flettner rotor and without flettner rotor.

The first step on this process is to calculate the time taken for a voyage without a flettner rotor. It will be calculated by using the formula:

$$
\mathbf{t}(\text { hour })=\frac{d(\mathrm{~km})}{v(\mathrm{~km} / \mathrm{h})}
$$

Now once the time taken is already determined, proceeding to the calculation of main engine and auxiliary engine consumption calculation. For the main engine, it is calculated by using the formula of

$$
\mathrm{m}(\mathrm{kg})=\frac{t(\text { hour }) \times M / E(k W) \times M E S F O C\left(\frac{g}{\mathrm{kWH}}\right)}{(1000)}
$$

For the auxiliary engine, it is calculated by using the formula of

$$
\mathrm{m}(\mathrm{kg})=\frac{t(\text { hour }) \times A / E(k W) \times A E S F O C\left(\frac{g}{k W H}\right)}{(1000)}
$$

For the Flettner Rotor, it is calculated by using the formula of

$$
\mathrm{m}(\mathrm{kg})=\frac{t(\text { hour }) \times F R(k W) \times A E S F O C\left(\frac{g}{\mathrm{kWH}}\right)}{(1000)}
$$

These formulas will be used to compare the operation between ship with flettner rotor and ship without flettner rotor on varied distance.

\section{RESULT AND DISCUSSION}

1) Ship Resistance Result

The calculation done by using the Maxsurf resistance software. It is based on the selected ship model that has

\begin{tabular}{|c|c|c|c|c|c|}
\hline & $\begin{array}{l}\text { Speed } \\
\text { (kn) }\end{array}$ & $\begin{array}{l}\text { Froude No. } \\
\text { LWL }\end{array}$ & $\begin{array}{c}\text { Froude No. } \\
\text { Vol. }\end{array}$ & $\begin{array}{c}\text { Holtrop } \\
\text { Resist. } \\
\text { (kN) }\end{array}$ & $\begin{array}{c}\text { Holtrop } \\
\text { Power } \\
(\text { kW) }\end{array}$ \\
\hline 1 & 12.000 & 0.185 & 0.570 & 88.5 & 546.251 \\
\hline 2 & 12.100 & 0.187 & 0.575 & 90.0 & 560.371 \\
\hline 3 & 12.200 & 0.188 & 0.580 & 91.6 & 574.758 \\
\hline 4 & 12.300 & 0.190 & 0.584 & 93.1 & 589.414 \\
\hline 5 & 12.400 & 0.191 & 0.589 & 94.7 & 604.344 \\
\hline 6 & 12.500 & 0.193 & 0.594 & 96.3 & 619.552 \\
\hline 7 & 12.600 & 0.194 & 0.599 & 98.0 & 635.039 \\
\hline 8 & 12.700 & 0.196 & 0.603 & 99.6 & 650.811 \\
\hline 9 & 12.800 & 0.197 & 0.608 & 101.3 & 666.871 \\
\hline 10 & 12.900 & 0.199 & 0.613 & 103.0 & 683.223 \\
\hline 11 & 13.000 & 0.200 & 0.618 & 104.6 & 699.870 \\
\hline 12 & 13.100 & 0.202 & 0.622 & 106.4 & 716.817 \\
\hline 13 & 13.200 & 0.204 & 0.627 & 108.1 & 734.067 \\
\hline 14 & 13.300 & 0.205 & 0.632 & 109.9 & 751.625 \\
\hline 15 & 13.400 & 0.207 & 0.637 & 111.6 & 769.495 \\
\hline 16 & 13.500 & 0.208 & 0.641 & 113.4 & 787.680 \\
\hline 17 & 13.600 & 0.210 & 0.646 & 115.2 & 806.186 \\
\hline 18 & 13.700 & 0.211 & 0.651 & 117.1 & 825.016 \\
\hline 19 & 13.800 & 0.213 & 0.656 & 118.9 & 844.174 \\
\hline 20 & 13.900 & 0.214 & 0.660 & 120.8 & 863.665 \\
\hline 21 & 14.000 & 0.216 & 0.665 & 122.7 & 883.491 \\
\hline 22 & 14.100 & 0.217 & 0.670 & 124.6 & 903.658 \\
\hline 23 & 14.200 & 0.219 & 0.675 & 126.5 & 924.168 \\
\hline 24 & 14.300 & 0.221 & 0.679 & 128.5 & 945.025 \\
\hline 25 & 14.400 & 0.222 & 0.684 & 130.4 & 966.231 \\
\hline 26 & 14.500 & 0.224 & 0.689 & 132.4 & 987.790 \\
\hline 27 & 14.600 & 0.225 & 0.694 & 134.4 & 1009.704 \\
\hline 28 & 14.700 & 0.227 & 0.698 & 136.5 & 1031.975 \\
\hline 29 & 14.800 & 0.228 & 0.703 & 138.5 & 1054.605 \\
\hline 30 & 14.900 & 0.230 & 0.708 & 140.6 & 1077.595 \\
\hline 31 & 15.000 & 0.231 & 0.713 & 142.7 & 1100.948 \\
\hline 32 & $1510 n$ & ก 233 & 0717 & 1448 & 1124 66? \\
\hline
\end{tabular}
been chosen. The methods used for the calculation is by using the holtrop method and done in several different ship speed.

Figure. 4. Resistance result. 
2) Flettner Rotor Creation

TABLE 1.

LIFT FORCE RESULT

\begin{tabular}{cccc}
\hline No & Flux Vel $(\mathrm{m} / \mathrm{s})$ & Rotation $(\mathrm{rad} / \mathrm{s})$ & Lift $(\mathrm{N})$ \\
\hline 1 & 7.2 & 14.4 & 31912.7 \\
2 & 6.9 & 13.8 & 29308.72 \\
3 & 6.3 & 12.6 & 24433.16 \\
4 & 5.6 & 11.2 & 19305.22 \\
5 & 4.5 & 9 & 12465.9 \\
6 & 2.7 & 5.4 & 4487.724 \\
& & & \\
& DRAG FORCE RESULT & \\
No & Flux Vel (m/s) & Rotation (rad/s) & Drag $(\mathrm{N})$ \\
\hline 1 & 7.2 & 14.4 & 1866.24 \\
2 & 6.9 & 13.8 & 1788.48 \\
3 & 6.3 & 12.6 & 1632.96 \\
4 & 5.6 & 11.2 & 1451.52 \\
5 & 4.5 & 9 & 696.84 \\
\hline 6 & 2.7 & 5.4 &
\end{tabular}

\begin{tabular}{|c|c|c|c|c|c|c|c|c|c|c|c|}
\hline \multirow{2}{*}{ No } & \multirow{2}{*}{\begin{tabular}{|l|} 
Diameter \\
(meter) \\
\end{tabular}} & \multirow{2}{*}{ Material } & \multirow{2}{*}{$\frac{\text { Density }}{(\mathrm{kg} / \mathrm{m} 3)}$} & \multirow{2}{*}{$\begin{array}{c}\text { Mass } \\
(\mathrm{kg})\end{array}$} & \multicolumn{2}{|c|}{ R Angular Velocity } & \multirow{2}{*}{$\begin{array}{l}\text { Time } \\
\text { (secon) }\end{array}$} & \multirow{2}{*}{$\begin{array}{c}\alpha \text { Angular Acc. } \\
(\mathrm{rad} / \mathrm{s} 2)\end{array}$} & \multirow{2}{*}{$\begin{array}{l}\text { I(Inertia Moment) } \\
(\mathrm{kg} / \mathrm{m} 2)\end{array}$} & \multirow{2}{*}{$\frac{\text { T(Torque) }}{(\mathrm{Nm})}$} & \multirow{2}{*}{$\begin{array}{c}\text { Power Rotor Consumption } \\
(\mathrm{kW})\end{array}$} \\
\hline & & & & & $(\mathrm{rad} / \mathrm{s})$ & (RPM) & & & & & \\
\hline 1 & 3 & S. Steel & 8000 & 3617.31 & 14.4 & 137.508 & 10 & 1.44 & 8138.93625 & 11720.1 & 228.8226685 \\
\hline 2 & 3 & S. Steel & 8000 & 3617.31 & 13.8 & 131.779 & 10 & 1.38 & 8138.93625 & 11231.7 & 210.1513744 \\
\hline 3 & 3 & S. Steel & 8000 & 3617.31 & 12.6 & 120.32 & 10 & 1.26 & 8138.93625 & \begin{tabular}{|l|}
10255.1 \\
\end{tabular} & 175.1923556 \\
\hline 4 & 3 & S. Steel & 8000 & 3617.31 & 11.2 & 106.951 & 10 & 1.12 & 8138.93625 & 9115.61 & 138.4235896 \\
\hline 5 & 3 & S. Steel & 8000 & 3617.31 & 9 & 85.9428 & 10 & 0.9 & 8138.93625 & 7325.04 & 89.38385489 \\
\hline 6 & 3 & S. Steel & 8000 & 3617.31 & 5.4 & 51.5657 & 10 & 0.54 & 8138.93625 & 4395.03 & 32.17818776 \\
\hline 7 & 3 & Alumunium & 2700 & 1220.84 & 14.4 & 137.508 & 10 & 1.44 & 2746.89 & 3955.52 & 77.22762295 \\
\hline 8 & 3 & Alumunium & 2700 & 1220.84 & 13.8 & 131.779 & 10 & 1.38 & 2746.89 & 3790.71 & 70.92606344 \\
\hline 9 & 3 & Alumunium & 2700 & 1220.84 & 12.6 & 120.32 & 10 & 1.26 & 2746.89 & 3461.08 & 59.12739882 \\
\hline 10 & 3 & Alumunium & 2700 & 1220.84 & 11.2 & 106.951 & 10 & 1.12 & 2746.89 & 3076.52 & 46.71794475 \\
\hline 11 & 3 & Alumunium & 2700 & 1220.84 & 9 & 85.9428 & 10 & 0.9 & 2746.89 & \begin{tabular}{|l|}
2472.2 \\
\end{tabular} & 30.16704022 \\
\hline 12 & 3 & Alumunium & 2700 & 1220.84 & 5.4 & 51.5657 & 10 & 0.54 & 2746.89 & \begin{tabular}{|l|}
1483.32 \\
\end{tabular} & 10.86013448 \\
\hline 13 & 3 & Steel & 7850 & 3549.48 & 14.4 & 137.508 & 10 & 1.44 & 7986.33225 & 11500.3 & 224.5322731 \\
\hline 14 & 3 & Steel & 7850 & 3549.48 & 13.8 & 131.779 & 10 & 1.38 & 7986.33225 & 11021.1 & 206.2110634 \\
\hline 15 & 3 & Steel & 7850 & 3549.48 & 12.6 & 120.32 & 10 & 1.26 & 7986.33225 & 10062.8 & 171.9075216 \\
\hline 16 & 3 & Steel & 7850 & 3549.48 & 11.2 & 106.951 & 10 & 1.12 & 7986.33225 & 8944.69 & 135.8281652 \\
\hline 17 & 3 & Steel & 7850 & 3549.48 & 9 & 85.9428 & 10 & 0.9 & 7986.33225 & \begin{tabular}{|l|}
7187.7 \\
\end{tabular} & 87.70791919 \\
\hline 18 & 3 & Steel & 7850 & 3549.48 & 5.4 & 51.5657 & 10 & 0.54 & 7986.33225 & 4312.62 & 31.57485091 \\
\hline 19 & 3 & Zinc & 7000 & 3165.14 & 14.4 & 137.508 & 10 & 1.44 & 7121.5695 & \begin{tabular}{|l|}
0255.1 \\
\end{tabular} & 200.2198429 \\
\hline 20 & 3 & Zinc & 7000 & 3165.14 & 13.8 & 131.779 & 10 & 1.38 & 7121.5695 & \begin{tabular}{|l|l|}
9827.77 \\
\end{tabular} & 183.8824599 \\
\hline 21 & 3 & Zinc & 7000 & 3165.14 & 12.6 & 120.32 & 10 & 1.26 & 7121.5695 & 8973.18 & 153.2933172 \\
\hline 22 & 3 & Zinc & 7000 & 3165.14 & 11.2 & 106.951 & 10 & 1.12 & 7121.5695 & 7976.16 & 121.1206457 \\
\hline 23 & 3 & Zinc & 7000 & 3165.14 & 9 & 85.9428 & 10 & 0.9 & 7121.5695 & 6409.41 & 78.21087612 \\
\hline 24 & 3 & Zinc & 7000 & 3165.14 & 5.4 & 51.5657 & 10 & 0.54 & 7121.5695 & 3845.65 & 28.1559154 \\
\hline
\end{tabular}

Figure. 5. Flettner rotor variation.

The Flettner rotor creation process done in several variation. It varies in the value of density of material, wind speed, and rotation speed. Now the result of the calculation indicates that the higher density of the material used the higher power needs to rotate the flettner rotor. It can also be seen that different wind speed that attacks flettner rotor produce different force as the higher the wind speeds the more force produced by the flettner rotor. this paper, rotor's parameter such as its dimension, RPM, and the other is referring to the graph Figure 1 created by (A. De Marco, S.
Mancini, C. Pensa, R. Scognamiglio, and L. Vitiello). There stated various value of SR, AR, $\mathrm{CL}$, and $\mathrm{CD}$. Each of these values are important and represent several factors to be selected in the process of designing Flettner Rotor.

3) Simulation Result

This is the most important stage as the force produced by the simulation will be used for later wind direction \& energy efficiency analysis. Based on the simulation, the flettner rotor produce such amount of lift and drag force that the result is not too far with the calculation by using an equation. 
International Journal of Marine Engineering Innovation and Research, Vol. 5(2), Jun. 2020. 92-101 (pISSN: 2541-5972, eISSN: 2548-1479)

\begin{tabular}{|c|c|c|c|c|c|c|}
\hline \multicolumn{7}{|c|}{ Force Based on Simulation } \\
\hline Rotation $(\mathrm{rad} / \mathrm{s})$ & Wind Speed $(\mathrm{m} / \mathrm{s})$ & Force X (N) & Force $\mathrm{Y}(\mathrm{N})$ & Force Resultant $(\mathrm{N})$ & Cos & Direction From $\mathrm{Y}$ \\
\hline 14.4 & 7.2 & -1219.6848 & 26901.3582 & 26928.99371 & 0.999848 & 0.998973763 \\
\hline 13.8 & 6.9 & -1184.6111 & 25025.3936 & 25053.41547 & 0.999848 & 0.998881514 \\
\hline 12.6 & 6.3 & -976.24295 & 20491.3572 & 20514.59899 & 0.999848 & 0.998867063 \\
\hline 11.2 & 5.6 & -775.41935 & 16209.0434 & 16227.58036 & 0.999848 & 0.99885769 \\
\hline 9 & 4.5 & -501.21541 & 10450.6943 & 10462.70656 & 0.999848 & 0.998851899 \\
\hline 5.4 & 2.7 & -182.34852 & 3756.01251 & 3760.436269 & 0.9998481 & 0.998823604 \\
\hline
\end{tabular}

Figure. 6. Flettner rotor simulation result.

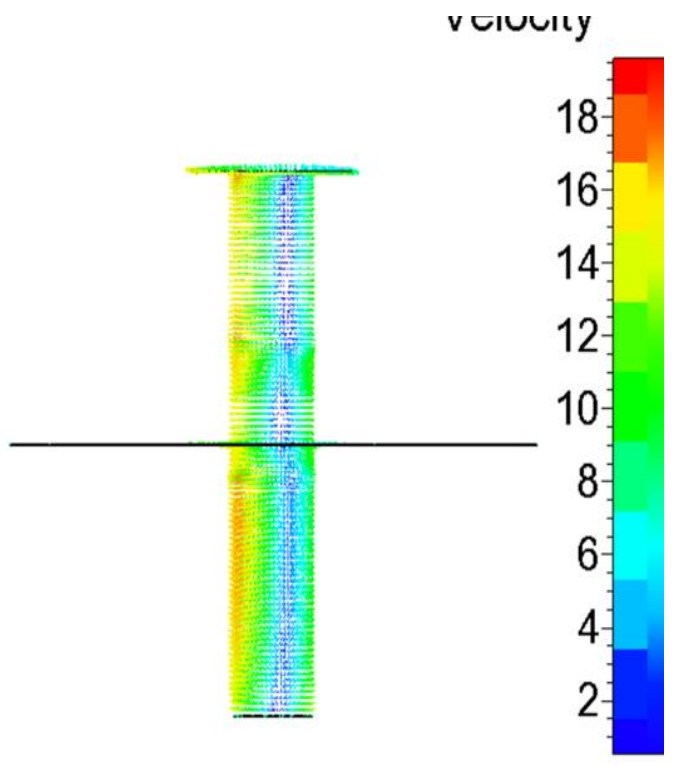

Figure. 7. Flettner rotor simulation visual result.

Based on the simulation result, the flettner rotor produce a lift the other side it increases the value of pressure. This force towards the $\mathrm{Y}+$ direction and a drag force towards the $\mathrm{X}$ direction. On the visual side, the red area indicates a high differences make a lift from the high pressure area towards the low pressure area ( $\mathrm{Y}$ - towards $\mathrm{Y}+$ ). velocity area which creates pressure drop on the faces while on

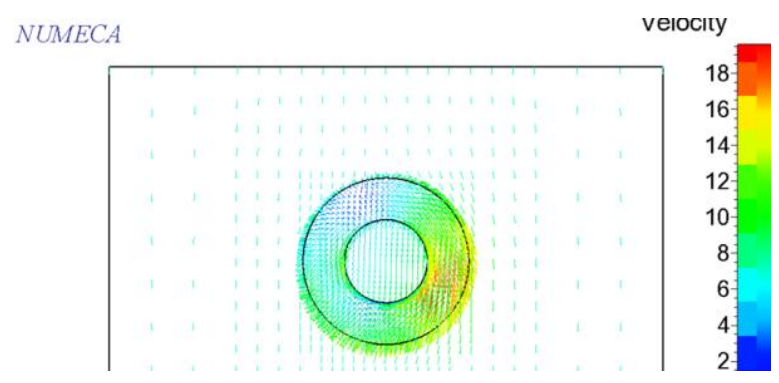

Figure. 8. Flettner Rotor $7.2 \mathrm{~m} / \mathrm{s}$ at $14.4 \mathrm{rad} / \mathrm{s}$.

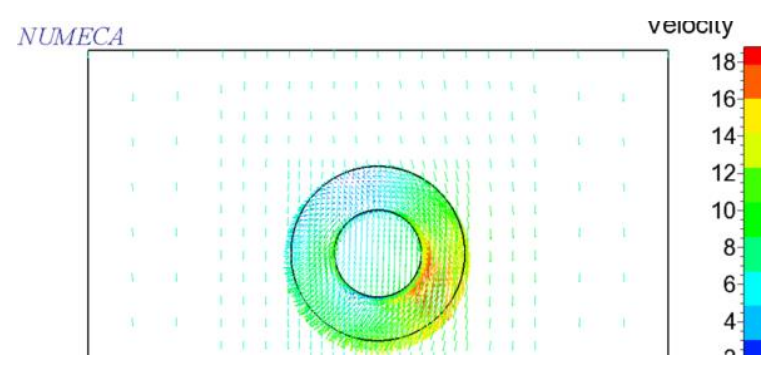

Figure. 9. Flettner Rotor $6.9 \mathrm{~m} / \mathrm{s}$ at $13.8 \mathrm{rad} / \mathrm{s}$. 


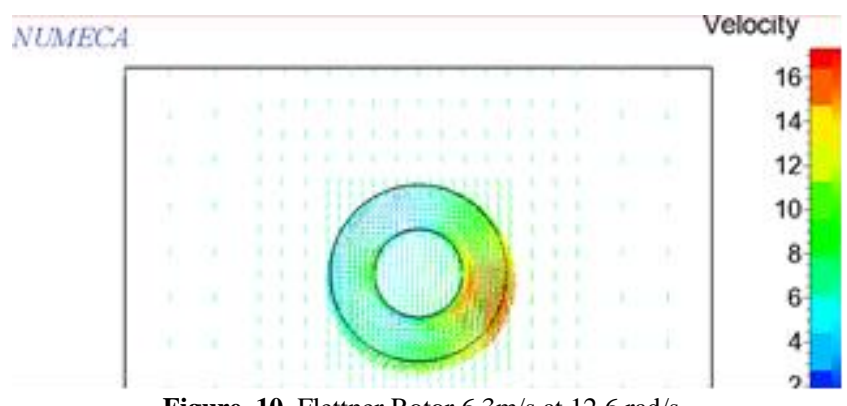

Figure. 10. Flettner Rotor $6.3 \mathrm{~m} / \mathrm{s}$ at $12.6 \mathrm{rad} / \mathrm{s}$.

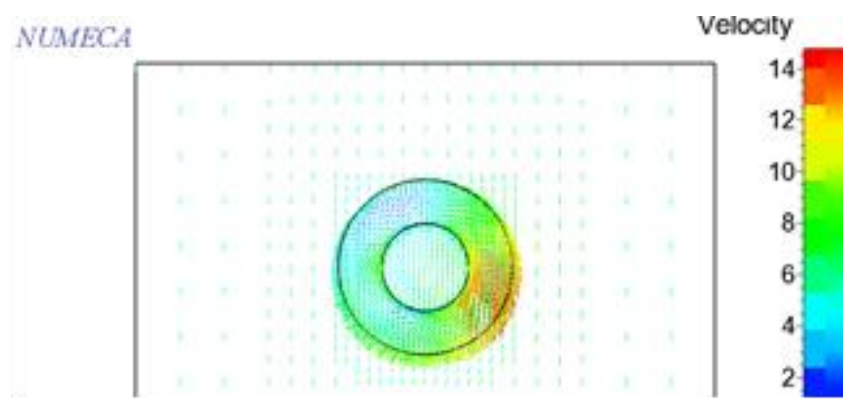

Figure. 11. Flettner Rotor $5.6 \mathrm{~m} / \mathrm{s}$ at $11.2 \mathrm{rad} / \mathrm{s}$

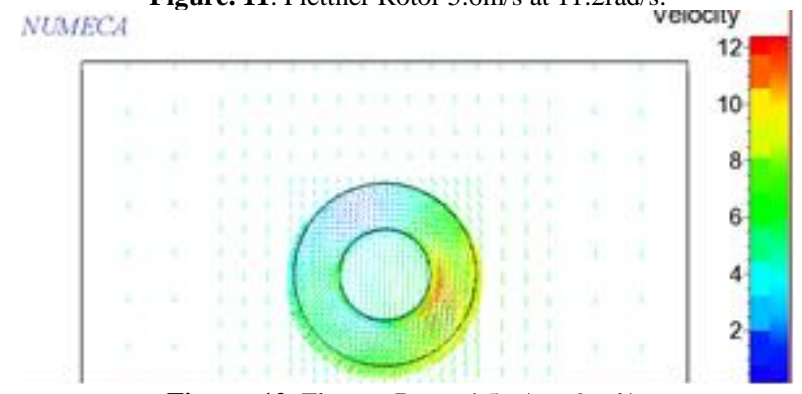

Figure. 12. Flettner Rotor $4.5 \mathrm{~m} / \mathrm{s}$ at $9 \mathrm{rad} / \mathrm{s}$.

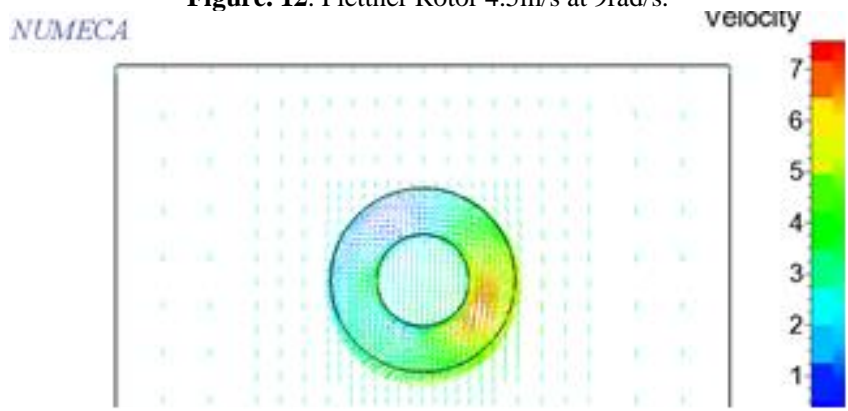

4) Wind Direction Analysis

Figure. 13. Flettner Rotor $2.7 \mathrm{~m} / \mathrm{s}$ at $4.5 \mathrm{rad} / \mathrm{s}$.
The force value is obtained, the force resultant and the direction is obtained as well. Now, the process proceeding to see how the force produce by the flettner is working on the ship moving to the desired direction on various wind angle. This process will be done by using vector lines on
Autocad software to determine its effect on the ship. The first thing to do is to prepare the data for the process. Several data needed for this process are ship's resistance, force resultant for each flettner rotor different parameter, force directions, and ship directions. 
International Journal of Marine Engineering Innovation and Research, Vol. 5(2), Jun. 2020. 92-101 (pISSN: 2541-5972, eISSN: 2548-1479)

\begin{tabular}{|c|c|c|c|c|c|c|c|}
\hline \multicolumn{8}{|c|}{ Starboard Side } \\
\hline \begin{tabular}{|l|} 
Wind Speed \\
\end{tabular} & Ship Spee & Direction (Degree) & Ship Resis & Force Resultan & Result & Speed After & Direction \\
\hline $\mathrm{m} / \mathrm{s}$ & Knot & $\circ$ & $\mathrm{N}$ & $\mathrm{N}$ & $\mathrm{N}$ & $\mathrm{kn}$ & $\circ$ \\
\hline 7.2 & 15 & 0 & 142700 & 26928.99371 & 144756 & 15.1 & 11 \\
\hline 7.2 & 15 & 15 & 142700 & 26928.99371 & 1377416 & 14.765 & 11 \\
\hline 7.2 & 15 & 30 & 142700 & 26928.99371 & 130863 & 14.422 & 10 \\
\hline 7.2 & 15 & 45 & 142700 & 26928.99371 & 124748 & 14.108 & 9 \\
\hline 7.2 & 15 & 60 & 142700 & 26928.99371 & 119843 & 13.85 & 6 \\
\hline 7.2 & 15 & 75 & 142700 & 26928.99371 & 116747 & 13.68 & 3 \\
\hline 7.2 & 15 & 90 & 142700 & 26928.99371 & 115776 & 13.638 & 0 \\
\hline 7.2 & 15 & 105 & 142700 & 26928.99371 & 117044 & 13.69 & 4 \\
\hline 7.2 & 15 & 120 & 142700 & 26928.99371 & 120410 & 13.86 & 7 \\
\hline 7.2 & 15 & 135 & 142700 & 26928.99371 & 125504 & 14.153 & 9 \\
\hline 7.2 & 15 & 150 & 142700 & 26928.99371 & 131762 & 14.475 & 10 \\
\hline 7.2 & 15 & 165 & 142700 & 26928.99371 & 138641 & 14.81 & 11 \\
\hline 7.2 & 15 & 180 & 142700 & 26928.99371 & 145669 & 15.15 & 11 \\
\hline 6.9 & 15 & 0 & 142700 & 25053.41547 & 144416 & 15.087 & 10 \\
\hline 6.9 & 15 & 15 & 142700 & 25053.41547 & 137923 & 14.765 & 10 \\
\hline 6.9 & 15 & 30 & 142700 & 25053.41547 & 131561 & 14.46 & 9 \\
\hline 6.9 & 15 & 45 & 142700 & 25053.41547 & 125896 & 14.165 & 8 \\
\hline 6.9 & 15 & 60 & 142700 & 25053.41547 & 121397 & 13.928 & 6 \\
\hline 6.9 & 15 & 75 & 142700 & 25053.41547 & 118543 & 13.78 & 3 \\
\hline 6.9 & 15 & 90 & 142700 & 25053.41547 & 117651 & 13.73 & 0 \\
\hline 6.9 & 15 & 105 & 142700 & 25053.41547 & 118829 & 13.79 & 3 \\
\hline 6.9 & 15 & 120 & 142700 & 25053.41547 & 121929 & 13.96 & 6 \\
\hline 6.9 & 15 & 135 & 142700 & 25053.41547 & 126592 & 14.205 & 8 \\
\hline 6.9 & 15 & 150 & 142700 & 25053.41547 & 132370 & 14.49 & 10 \\
\hline 6.9 & 15 & 165 & 142700 & 25053.41547 & 138810 & 14.815 & 10 \\
\hline 6.9 & 15 & 180 & 142700 & 25053.41547 & 145302 & 15.125 & 10 \\
\hline 6.3 & 15 & 0 & 142700 & 20514.59899 & 143821 & 15.06 & 8 \\
\hline 6.3 & 15 & 15 & 142700 & 20514.59899 & 138466 & 14.799 & 8 \\
\hline 6.3 & 15 & 30 & 142700 & 20514.59899 & 133309 & 14.548 & 8 \\
\hline 6.3 & 15 & 45 & 142700 & 20514.59899 & 128744 & 14.311 & 6 \\
\hline 6.3 & 15 & 60 & 142700 & 20514.59899 & 125163 & 14.128 & 5 \\
\hline 6.3 & 15 & 75 & 142700 & 20514.59899 & 122902 & 14.013 & 2 \\
\hline 6.3 & 15 & 90 & 142700 & 20514.59899 & 122198 & 13.966 & 0 \\
\hline 6.3 & 15 & 105 & 142700 & 20514.59899 & 123110 & 14.016 & 3 \\
\hline 6.3 & 15 & 120 & 142700 & 20514.59899 & 125560 & 14.164 & 5 \\
\hline 6.3 & 15 & 135 & 142700 & 20514.59899 & 129303 & 14.33 & 7 \\
\hline 6.3 & 15 & 150 & 142700 & 20514.59899 & 133969 & 14.575 & 8 \\
\hline 6.3 & 15 & 165 & 142700 & 20514.59899 & 139185 & 14.829 & 8 \\
\hline 6.3 & 15 & 180 & 142700 & 20514.59899 & 144538 & 15.087 & 8 \\
\hline
\end{tabular}

Figure. 14. Wind Direction from Starboard side.

\begin{tabular}{|c|c|c|c|c|c|c|c|}
\hline \multicolumn{8}{|c|}{ Port Side } \\
\hline Wind Speed & Ship Speed & Direction (Degree) & Ship Resis & \begin{tabular}{|l|} 
Force Resultan \\
\end{tabular} & Result & Speed After & Direction \\
\hline $\mathrm{m} / \mathrm{s}$ & Knot & $\cdot$ & $\mathrm{N}$ & $\mathrm{N}$ & $\mathrm{N}$ & $\mathrm{kn}$ & $\circ$ \\
\hline 7.2 & 15 & 0 & 142700 & 26928.99371 & 144756 & 15.1 & 11 \\
\hline 7.2 & 15 & 15 & 142700 & 26928.99371 & 151493 & 15.42 & 10 \\
\hline 7.2 & 15 & 30 & 142700 & 26928.99371 & 157725 & 15.7 & 9 \\
\hline 7.2 & 15 & 45 & 142700 & 26928.99371 & 162565 & 15.925 & 7 \\
\hline 7.2 & 15 & 60 & 142700 & 26928.99371 & 166400 & 16.1 & 5 \\
\hline 7.2 & 15 & 75 & 142700 & 26928.99371 & 168757 & 16.2 & 3 \\
\hline 7.2 & 15 & 90 & 142700 & 26928.99371 & 169624 & 16.224 & 0 \\
\hline 7.2 & 15 & 105 & 142700 & 26928.99371 & 168955 & 16.18 & 2 \\
\hline 7.2 & 15 & 120 & 142700 & 26928.99371 & 166763 & 16.1 & 4 \\
\hline 7.2 & 15 & 135 & 142700 & 26928.99371 & 163136 & 15.939 & 7 \\
\hline 7.2 & 15 & 150 & 142700 & 26928.99371 & 158251 & 15.75 & 8 \\
\hline 7.2 & 15 & 165 & 142700 & 26928.99371 & 152345 & 15.45 & 10 \\
\hline 7.2 & 15 & 180 & 142700 & 26928.99371 & 145678 & 15.15 & 11 \\
\hline 6.9 & 15 & 0 & 142700 & 25053.41547 & 144461 & 15.087 & 10 \\
\hline 6.9 & 15 & 15 & 142700 & 25053.41547 & 150743 & 15.375 & 9 \\
\hline 6.9 & 15 & 30 & 142700 & 25053.41547 & 156396 & 15.637 & 8 \\
\hline 6.9 & 15 & 45 & 142700 & 25053.41547 & 161115 & 15.84 & 6 \\
\hline 6.9 & 15 & 60 & 142700 & 25053.41547 & 164668 & 15.991 & 4 \\
\hline 6.9 & 15 & 75 & 142700 & 25053.41547 & 166910 & 16.1 & 2 \\
\hline 6.9 & 15 & 90 & 142700 & 25053.41547 & 167741 & 16.13 & 0 \\
\hline 6.9 & 15 & 105 & 142700 & 25053.41547 & 167112 & 16.12 & 2 \\
\hline 6.9 & 15 & 120 & 142700 & 25053.41547 & 166059 & 16.06 & 4 \\
\hline 6.9 & 15 & 135 & 142700 & 25053.41547 & 161672 & 15.85 & 6 \\
\hline 6.9 & 15 & 150 & 142700 & 25053.41547 & 157066 & 15.645 & 8 \\
\hline 6.9 & 15 & 165 & 142700 & 25053.41547 & 151530 & 15.413 & 9 \\
\hline 6.9 & 15 & 180 & 142700 & 25053.41547 & 145329 & 15.12 & 10 \\
\hline 6.3 & 15 & 0 & 142700 & 20514.59899 & 143821 & 15.06 & 8 \\
\hline 6.3 & 15 & 15 & 142700 & 20514.59899 & 149008 & 15.296 & 8 \\
\hline 6.3 & 15 & 30 & 142700 & 20514.59899 & 153696 & 15.51 & 7 \\
\hline 6.3 & 15 & 45 & 142700 & 20514.59899 & 157624 & 15.68 & 5 \\
\hline 6.3 & 15 & 60 & 142700 & 20514.59899 & 160632 & 15.825 & 4 \\
\hline 6.3 & 15 & 75 & 142700 & 20514.59899 & 162517 & 15.91 & 2 \\
\hline 6.3 & 15 & 90 & 142700 & 20514.59899 & 163211 & 15.93 & 0 \\
\hline 6.3 & 15 & 105 & 142700 & 20514.59899 & 162684 & 15.915 & 2 \\
\hline 6.3 & 15 & 120 & 142700 & 20514.59899 & 160949 & 15.83 & 4 \\
\hline 6.3 & 15 & 135 & 142700 & 20514.59899 & 158111 & 15.71 & 5 \\
\hline 6.3 & 15 & 150 & 142700 & 20514.59899 & 154270 & 15.53 & 7 \\
\hline 6.3 & 15 & 165 & 142700 & 20514.59899 & 149675 & 15.328 & 8 \\
\hline 6.3 & 15 & 180 & 142700 & 20514.59899 & 144538 & 15.087 & 8 \\
\hline
\end{tabular}

Figure. 15. Wind Direction from Port side.

Based on the table above, the best wind direction for the flettner rotor on this paper is at $90^{\circ}$ from the port side, producing the biggest resultant force which resulting in the rising of ship's speed. 
International Journal of Marine Engineering Innovation and Research, Vol. 5(2), Jun. 2020. 92-101 (pISSN: 2541-5972, eISSN: 2548-1479)

5) Energy Efficiency Analysis

On this stage, the energy efficiency analysis is conduct by comparing the fuel consumption of ship with flettner rotor and fuel consumption of ship without flettner rotor.

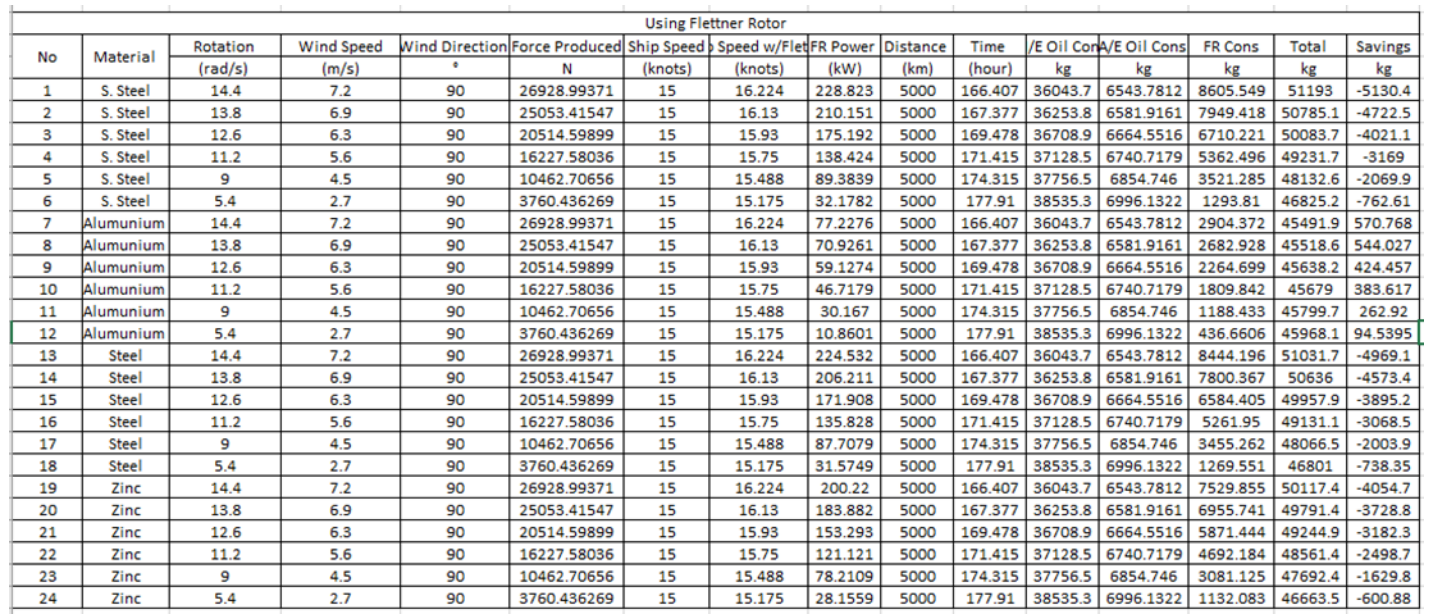

Figure. 16. Fuel savings for $5000 \mathrm{~km}$ voyage with FR.

\begin{tabular}{|c|c|c|c|c|c|c|c|c|c|c|c|c|c|c|c|}
\hline \multicolumn{16}{|c|}{ Using Flettner Rotor } \\
\hline No & Material & Rotation & Wind Speed & Wind Directior & Force Produced & Ship Speed & speed w/F & AFR Power & istance & Time & /E Oil con & A/E Oil Cons & FR Cons & Total & Savings \\
\hline & & $(\mathrm{rad} / \mathrm{s})$ & $(\mathrm{m} / \mathrm{s})$ & $\cdot$ & $\mathrm{N}$ & (knots) & (knots) & $(\mathrm{kW})$ & $(\mathrm{km})$ & (hour) & $\mathrm{kg}$ & $\mathrm{kg}$ & $\mathrm{kg}$ & $\mathrm{kg}$ & $\mathrm{kg}$ \\
\hline 1 & S. Steel & 14.4 & 7.2 & 90 & 26928.99371 & 15 & 16.224 & 228.823 & 2500 & 83.2034 & $\mid 18021.9$ & 3271.8906 & 4302.774 & 25596.5 & -2565.2 \\
\hline 2 & S. Steel & 13.8 & 6.9 & 90 & 25053.41547 & 15 & 16.13 & 210.151 & 2500 & 83.6883 & 18126.9 & 3290.9581 & 3974.709 & 25392.5 & -2361.2 \\
\hline 3 & S. Steel & 12.6 & 6.3 & 90 & 20514.59899 & 15 & 15.93 & 175.192 & 2500 & 84.739 & 18354.5 & 3332.2758 & \begin{tabular}{|l|l|}
3355.111 \\
\end{tabular} & 25041.9 & -2010.5 \\
\hline 4 & S. Steel & 11.2 & 5.6 & 90 & 16227.58036 & 15 & 15.75 & 138.424 & 2500 & 85.7074 & 18564.2 & 3370.3589 & 2681.248 & 24615.8 & -1584.5 \\
\hline 5 & S. Steel & 9 & 4.5 & 90 & 10462.70656 & 15 & 15.488 & 89.3839 & 2500 & 87.1573 & \begin{tabular}{|l|}
18878.3 \\
\end{tabular} & 3427.373 & \begin{tabular}{|l|}
1760.643 \\
\end{tabular} & 24066.3 & -1035 \\
\hline 6 & S. Steel & 5.4 & 2.7 & 90 & \begin{tabular}{|l|l|}
3760.436269 \\
\end{tabular} & 15 & 15.175 & 32.1782 & 2500 & 88.955 & 19267.7 & 3498.0661 & 646.9048 & 23412.6 & -381.3 \\
\hline 7 & Alumunium & 14.4 & 7.2 & 90 & 26928.99371 & 15 & 16.224 & 77.2276 & 2500 & 83.2034 & 18021.9 & 3271.8906 & 1452.186 & 22745.9 & 285.384 \\
\hline 8 & Alumunium & 13.8 & 6.9 & 90 & 25053.41547 & 15 & 16.13 & 70.9261 & 2500 & 83.6883 & \begin{tabular}{|l|}
18126.9 \\
\end{tabular} & 3290.9581 & \begin{tabular}{|l|l|}
1341.464 \\
\end{tabular} & \begin{tabular}{|l|l|}
22759.3 \\
\end{tabular} & 272.014 \\
\hline 9 & Alumunium & 12.6 & 6.3 & 90 & 20514.59899 & 15 & 15.93 & 59.1274 & 2500 & 84.739 & 18354.5 & 3332.2758 & 1132.349 & 22819.1 & 212.228 \\
\hline 10 & Alumunium & 11.2 & 5.6 & 90 & \begin{tabular}{|l|l}
16227.58036 \\
\end{tabular} & 15 & 15.75 & 46.7179 & 2500 & 85.7074 & \begin{tabular}{|l|l|} 
\\
\end{tabular} & 3370.3589 & 904.9209 & 22839.5 & 191.808 \\
\hline 11 & Alumunium & 9 & 4.5 & 90 & 10462.70656 & 15 & 15.488 & 30.167 & 2500 & 87.1573 & \begin{tabular}{|l|}
18878.3 \\
\end{tabular} & 3427.373 & \begin{tabular}{|l|}
594.2167 \\
\end{tabular} & 22899.9 & 131.46 \\
\hline 12 & Alumunium & 5.4 & 2.7 & 90 & 3760.436269 & 15 & 15.175 & 10.8601 & 2500 & 88.955 & \begin{tabular}{|l|}
19267.7 \\
\end{tabular} & 3498.0661 & 218.3303 & 22984 & 47.2698 \\
\hline 13 & Steel & 14.4 & 7.2 & 90 & 26928.99371 & 15 & 16.224 & 224.532 & 2500 & 83.2034 & 18021.9 & 3271.8906 & \begin{tabular}{|l|l|}
4222.098 \\
\end{tabular} & 25515.8 & -2484.5 \\
\hline 14 & Steel & 13.8 & 6.9 & 90 & 25053.41547 & 15 & 16.13 & 206.211 & 2500 & 83.6883 & \begin{tabular}{|l|}
18126.9 \\
\end{tabular} & 3290.9581 & \begin{tabular}{|l|}
3900.184 \\
\end{tabular} & 25318 & \begin{tabular}{|l|}
-2286.7 \\
\end{tabular} \\
\hline 15 & Steel & 12.6 & 6.3 & 90 & 20514.59899 & 15 & 15.93 & \begin{tabular}{|l|l|}
171.908 \\
\end{tabular} & 2500 & \begin{tabular}{|l|l|}
84.739 \\
\end{tabular} & \begin{tabular}{|l|}
18354.5 \\
\end{tabular} & 3332.2758 & \begin{tabular}{|l|}
3292.203 \\
\end{tabular} & 24978.9 & \begin{tabular}{|l|l|}
-1947.6 \\
\end{tabular} \\
\hline 16 & Steel & 11.2 & 5.6 & 90 & \begin{tabular}{|l|l|}
16227.58036 \\
\end{tabular} & 15 & 15.75 & 135.828 & 2500 & 85.7074 & \begin{tabular}{|l|l|} 
& 18564.2 \\
\end{tabular} & 3370.3589 & 2630.975 & 24565.6 & \begin{tabular}{|l|l|}
-1534.2 \\
\end{tabular} \\
\hline 17 & Steel & 9 & 4.5 & 90 & 10462.70656 & 15 & 15.488 & \begin{tabular}{|l|l|}
87.7079 \\
\end{tabular} & 2500 & 87.1573 & 18878.3 & 3427.373 & \begin{tabular}{|l|}
1727.631 \\
\end{tabular} & 24033.3 & -1002 \\
\hline 18 & Steel & 5.4 & 2.7 & 90 & 3760.436269 & 15 & 15.175 & 31.5749 & 2500 & 88.955 & \begin{tabular}{|l|}
19267.7 \\
\end{tabular} & 3498.0661 & \begin{tabular}{|l|l|}
634.7754 \\
\end{tabular} & 23400.5 & \begin{tabular}{|l|}
-369.18 \\
\end{tabular} \\
\hline 19 & Zinc & 14.4 & 7.2 & 90 & \begin{tabular}{|l|}
26928.99371 \\
\end{tabular} & 15 & 16.224 & 200.22 & 2500 & 83.2034 & \begin{tabular}{|l|}
18021.9 \\
\end{tabular} & \begin{tabular}{|l|l|}
3271.8906 \\
\end{tabular} & \begin{tabular}{|l|}
3764.928 \\
\end{tabular} & \begin{tabular}{|l|}
25058.7 \\
\end{tabular} & \begin{tabular}{|l|}
-2027.4 \\
\end{tabular} \\
\hline 20 & Zinc & 13.8 & 6.9 & 90 & \begin{tabular}{|l|l}
25053.41547 \\
\end{tabular} & 15 & 16.13 & \begin{tabular}{|l|l|}
183.882 \\
\end{tabular} & 2500 & 83.6883 & \begin{tabular}{|l|}
18126.9 \\
\end{tabular} & 3290.9581 & \begin{tabular}{|l|}
3477.87 \\
\end{tabular} & 24895.7 & -1864.4 \\
\hline 21 & Zinc & 12.6 & 6.3 & 90 & 20514.59899 & 15 & 15.93 & 153.293 & 2500 & 84.739 & 18354.5 & 3332.2758 & 2935.722 & 24622.5 & \begin{tabular}{|l|l|}
-1591.1 \\
\end{tabular} \\
\hline 22 & Zinc & 11.2 & 5.6 & 90 & 16227.58036 & 15 & 15.75 & 121.121 & 2500 & 85.7074 & \begin{tabular}{|l|}
18564.2 \\
\end{tabular} & 3370.3589 & 2346.092 & 24280.7 & \begin{tabular}{|l|}
-1249.4 \\
\end{tabular} \\
\hline 23 & Zinc & 9 & 4.5 & 90 & 10462.70656 & 15 & 15.488 & 78.2109 & 2500 & 87.1573 & \begin{tabular}{|l|}
18878.3 \\
\end{tabular} & 3427.373 & \begin{tabular}{|l|}
1540.562 \\
\end{tabular} & \begin{tabular}{|l|}
23846.2 \\
\end{tabular} & -814.89 \\
\hline 24 & Zinc & 5.4 & 2.7 & 90 & 3760.436269 & 15 & 15.175 & 28.1559 & 2500 & 88.955 & \begin{tabular}{|l|}
19267.7 \\
\end{tabular} & \begin{tabular}{|l|}
3498.0661 \\
\end{tabular} & \begin{tabular}{|l|l|}
566.0417 \\
\end{tabular} & 23331.8 & \begin{tabular}{|l|l|}
-300.44 \\
\end{tabular} \\
\hline
\end{tabular}

Figure. 17. Fuel savings for $2500 \mathrm{~km}$ voyage with FR

\begin{tabular}{|c|c|c|c|c|c|c|c|c|c|c|c|c|c|c|c|}
\hline \multicolumn{16}{|c|}{ Ir RC } \\
\hline & Materia & Rotation & Wind Speed & Wind Direc & Force Pro & Ship Speed & Speed w/Fl & AFR Power & Distance & Time & /E Oil con & A/E Oil Cons & FR Cons & Total & $\frac{\text { Savin }}{\mathrm{kg}}$ \\
\hline No & Materia & $(\mathrm{rad} / \mathrm{s})$ & $(\mathrm{m} / \mathrm{s})$ & $\bullet$ & $\mathrm{N}$ & (knots) & (knots) & $(\mathrm{kW})$ & $(\mathrm{km})$ & (hour) & $\mathrm{kg}$ & $\mathrm{kg}$ & $\mathrm{kg}$ & $\mathrm{kg}$ & \\
\hline 1 & S. Steel & 14.4 & 7.2 & 90 & 26928.99371 & 15 & 16.224 & 228.823 & 1000 & 33.2814 & 7208.74 & 1308.7562 & \begin{tabular}{|l|}
1721.11 \\
\end{tabular} & 10238.6 & -1026.1 \\
\hline 2 & S. Steel & 13.8 & 6.9 & 90 & 25053.41547 & 15 & 16.13 & 210.151 & 1000 & 33.4753 & 7250.75 & 1316.3832 & \begin{tabular}{|l|l|}
1589.884 \\
\end{tabular} & 10157 & -944.49 \\
\hline 3 & S. Steel & 12.6 & 6.3 & 90 & 20514.59899 & 15 & 15.93 & 175.192 & 1000 & 33.8956 & 7341.79 & \begin{tabular}{|l|l|}
1332.9103 \\
\end{tabular} & \begin{tabular}{|l|}
1342.044 \\
\end{tabular} & 10016.7 & -804.21 \\
\hline 4 & iteel & 11.2 & 5.6 & 90 & 16227.58036 & 15 & 15.75 & 138.424 & 1000 & 34.283 & 7425.69 & 1348.1436 & \begin{tabular}{|l|}
1072.499 \\
\end{tabular} & 9846.33 & -633 \\
\hline 5 & S. Steel & 9 & 4.5 & 90 & \begin{tabular}{|l}
10462.70656 \\
\end{tabular} & 15 & 15.488 & 89.3839 & 1000 & 34.8629 & 7551.31 & 1370.9492 & \begin{tabular}{|l|}
704.257 \\
\end{tabular} & 9626.51 & -413.99 \\
\hline 6 & S. Steel & 5.4 & 2.7 & 90 & 3760.436269 & 15 & 15.175 & 32.1782 & 1000 & 35.582 & 7707.06 & \begin{tabular}{|l|}
1399.2264 \\
\end{tabular} & 258.7619 & 9365.05 & -152.52 \\
\hline 7 & Alumunium & 14.4 & 7.2 & 90 & 26928.99371 & 15 & 16.224 & 77.2276 & 1000 & 33.2814 & 7208.74 & 1308.7562 & \begin{tabular}{|l|l|}
580.8743 \\
\end{tabular} & 9098.37 & \\
\hline 8 & Alumunium & 13.8 & 6.9 & 90 & 25053.41547 & 15 & 16.13 & 70.9261 & 1000 & 33.4753 & 7250.75 & 1316.3832 & 536.5855 & 9103.72 & 108.805 \\
\hline 9 & Alumunium & 12.6 & 6.3 & 90 & \begin{tabular}{|l}
20514.59899 \\
\end{tabular} & 15 & 15.93 & 59.1274 & 1000 & 33.8956 & 7341.79 & \begin{tabular}{|l|}
1332.9103 \\
\end{tabular} & \begin{tabular}{|l|}
452.9398 \\
\end{tabular} & 9127.64 & 84.8914 \\
\hline 10 & Alumunium & 11.2 & 5.6 & 90 & 16227.58036 & 15 & 15.75 & 46.7179 & 1000 & 34.283 & 7425.69 & \begin{tabular}{|l|l|}
1348.1436 \\
\end{tabular} & 361.9684 & 9135.8 & 76.7234 \\
\hline 11 & Alumunium & 9 & 4.5 & 90 & 10462.70656 & 15 & 15.488 & 30.167 & 1000 & \begin{tabular}{|l|l|}
34.8629 \\
\end{tabular} & \begin{tabular}{|l|}
7551.31 \\
\end{tabular} & 1370.9492 & \begin{tabular}{|l|}
237.6867 \\
\end{tabular} & \begin{tabular}{|l|l}
9159.94 \\
\end{tabular} & 52.5841 \\
\hline 12 & Alumunium & 5.4 & 2.7 & 90 & \begin{tabular}{|l}
3760.436269 \\
\end{tabular} & 15 & 15.175 & 10.8601 & 1000 & 35.582 & 7707.06 & \begin{tabular}{|l|}
1399.2264 \\
\end{tabular} & 87.33211 & 9193.62 & \begin{tabular}{|l|l|}
18.9079 \\
\end{tabular} \\
\hline 13 & Steel & 14.4 & 7.2 & 90 & \begin{tabular}{|l|}
26928.99371 \\
\end{tabular} & 15 & 16.224 & 224.532 & 1000 & 33.2814 & \begin{tabular}{|l|}
7208.74 \\
\end{tabular} & 1308.7562 & 1688.839 & 10206.3 & \begin{tabular}{|l|}
-993.81 \\
\end{tabular} \\
\hline 14 & Steel & 1 & 6.9 & 90 & 25053.41547 & 15 & 16.13 & 206.211 & 1000 & 33.4753 & 7250.75 & \begin{tabular}{|l|}
1316.3832 \\
\end{tabular} & \begin{tabular}{|l|l|}
1560.073 \\
\end{tabular} & 10127.2 & -914.68 \\
\hline 15 & Ste & 12.6 & 6.3 & 90 & \begin{tabular}{|l|l|}
20514.59899 \\
\end{tabular} & 15 & 15.93 & 171.908 & 1000 & 33.8956 & \begin{tabular}{|l|}
7341.79 \\
\end{tabular} & 1332.9103 & \begin{tabular}{|l|}
1316.881 \\
\end{tabular} & 9991.58 & \begin{tabular}{|l|}
-779.05 \\
\end{tabular} \\
\hline 16 & Steel & 11.2 & 5.6 & 90 & 16227.58036 & 15 & 15.75 & 135.828 & 1000 & 34.283 & 7425.69 & 1348.1436 & \begin{tabular}{|l|}
1052.39 \\
\end{tabular} & 9826.23 & \begin{tabular}{|l|}
-613.7 \\
\end{tabular} \\
\hline 17 & st & 9 & 4.5 & 90 & 10462.70656 & 15 & 15.488 & \begin{tabular}{|l|l|}
87.7079 \\
\end{tabular} & 1000 & 34.8629 & \begin{tabular}{|l|l|}
7551.31 \\
\end{tabular} & 1370.9492 & \begin{tabular}{|l|l|}
691.0523 \\
\end{tabular} & 9613.31 & \begin{tabular}{|l|}
-400.78 \\
\end{tabular} \\
\hline 18 & Steel & 5.4 & 2.7 & 90 & 3760.436269 & 15 & 15.175 & 31.5749 & 1000 & 35.582 & \begin{tabular}{|l|}
7707.06 \\
\end{tabular} & 1399.2264 & \begin{tabular}{|l|}
253.9102 \\
\end{tabular} & 9360.2 & -147.67 \\
\hline 19 & Zinc & 14.4 & 7.2 & 90 & 26928.99371 & 15 & 16.224 & 200.22 & 1000 & 33.2814 & 7208.74 & 1308.7562 & 1505.971 & 10023.5 & -810.94 \\
\hline 20 & Zinc & 13.8 & 6.9 & 90 & 25053.41547 & 15 & 16.13 & 183.882 & 1000 & 33.4753 & 7250.75 & 1316.3832 & \begin{tabular}{|l|l|}
1391.148 \\
\end{tabular} & 9958.28 & -745.76 \\
\hline 21 & $\mathrm{zi}$ & 12.6 & 6. & 90 & \begin{tabular}{|l|}
20514.59899 \\
\end{tabular} & 15 & 15.93 & 153.293 & 1000 & 33.8956 & 7341.79 & \begin{tabular}{|l|}
1332.9103 \\
\end{tabular} & \begin{tabular}{|l|l|}
1174.289 \\
\end{tabular} & 9848.98 & -636.46 \\
\hline 22 & $z_{i}$ & 11. & 5.6 & 90 & 16227.58036 & 15 & 15.75 & 121.121 & 1000 & 34.283 & 7425.69 & 1348.1436 & \begin{tabular}{|l|l|}
938.4369 \\
\end{tabular} & 9712.27 & \begin{tabular}{|c|}
-499.7 \\
\end{tabular} \\
\hline 23 & Zinc & 9 & 4.5 & 90 & 10462.70656 & 15 & 15.488 & 78.2109 & 1000 & 34.8629 & \begin{tabular}{|l|l|}
7551.31 \\
\end{tabular} & 1370.9492 & \begin{tabular}{|l|l|}
616.2249 \\
\end{tabular} & 9538.48 & -325.95 \\
\hline 24 & Zinc & 5.4 & 2.7 & 90 & 3760.436269 & 15 & 15.175 & 28.1559 & 1000 & 35.582 & \begin{tabular}{|l|}
7707.06 \\
\end{tabular} & \begin{tabular}{|l|}
1399.2264 \\
\end{tabular} & 226.4167 & 9332.7 & -120 \\
\hline
\end{tabular}

Figure. 18. Fuel savings for $1000 \mathrm{~km}$ voyage with FR.

It turns out that the flettner rotor using alumunium as a material can saved up to $570.768 \mathrm{~kg}$ on $5000 \mathrm{~km}$ voyage and in $2500 \mathrm{~km}$ voyage, it can save up until $285.34 \mathrm{~kg}$ of fuel. While in $1000 \mathrm{~km}$ voyage, it can save $114 \mathrm{~kg}$ of fuel.

\section{CONCLUSION}

Based on the result of simulation, calculation, and the analysis of flettner rotor on this paper, it can be concluded that:

1) Aluminum is the material that requires the least power to rotate the flettner rotor with 77.2276 $\mathrm{kW}$ power, on the speed of $14.4 \mathrm{rad} / \mathrm{s}$ and 
$10.881 \mathrm{~kW}$ power on the rotation speed of 5.4 $\mathrm{rad} / \mathrm{s}$.

2) Flettner Rotor gives its maximum contribution when wind direction towards the flettner rotor is coming through the port side of the ship with the angle of $90^{\circ}$. Meanwhile, if the wind direction towards the rotor is coming from the starboard side, it slows up the movement of the ship. These things depend on the direction of rotor's rotational movement whether it is counter- clockwise or not.

3) The best configuration of flettner rotor to produce a good energy efficiency on this paper are by using aluminum as the rotor's material, having wind that coming through from the angle of $90^{\circ}$, and the flettner rotor rotates at $14.4 \mathrm{rad} / \mathrm{s}$ with apparent wind speed at $7.2 \mathrm{~m} / \mathrm{s}$. This configuration can save fuel consumption of the ship up until $570.768 \mathrm{~kg}$ on $5000 \mathrm{~km}$ distance.

\section{REFERENCES}

[1] Arief, I. S., Santoso, A., \& Azzam, A. (2018). Design of Flettner Rotor in Container Carrier 4000 DWT with CFD. International Journal of Marine Engineering Innovation and Research, 2(2), 133-139.

[2] Bergeson, L. (1981). Wind Propulsion for Ships of the American Merchant Marine. Springfield: National Technical Information Service.

[3] De Marco, A., Mancini, S., Pensa, C., \& G.Calise, F. (2016). Flettner Rotor Concept for Marine Applications: A Systematic Study. International Journal of Rotating Machinery, 2016, 12.

[4] De Marco, A., Mancini, S., Pensa, C., \& Vitiello, L. (2015). MARINE APPLICATION OF FLETTNER ROTORS: NUMERICAL STUDY ON A SYSTEMATIC VARIATION OF GEOMETRIC FACTOR BY DOE APPROACH. Research Gate.

[5] Gleick, J. (2004). Isaac Newton . London: Harper Fourth Estate.

[6] Nuttall, P., \& Kaitu'u, J. (2016). The Magnus Effect and the Flettner Rotor:. The Journal of Pacific Studies, 36(2).

[7] Prandtl, L. (1926). Application of The "Magnus Effect" to the Wind Propulsion. Washington D.C.

[8] Rehmatulla, N., Parker, S., Smith, T., \& Stulgis, V. (2017). Wind Technologies: Opportunities and barriers to alow carbon shipping industry. Marine Policy, 75, 217-226.

[9] Sahiner, O. (2013). More Than Shipping. Retrieved 04 15, 2019, from https://www.morethanshipping.com/cleaner-logistics/

[10] Seifert, J. (2012). A review of the Magnus effect in aeronautics. Progress in Aerospace Sciences, 55, 17-45.

[11] Swanson, W. (1961). The Magnus Effect: A Summary of Investigations to Date. Journal of Basic Engineering, 83, 461-470.

[12] The New York Times. (1961). Anton Flettner. 